\title{
Índices para avaliar qualidade pós-colheita de goiabas em diferentes estádios de maturação
}

\author{
Marisa Azzolini(1), Angelo Pedro Jacomino(2) e llana Urbano Bron ${ }^{(3)}$
}

\begin{abstract}
(1)Escola Superior de Agricultura Luiz de Queiroz (Esalq), Dep. de Ciências Biológicas, Caixa Postal 09, CEP 13418-900 Piracicaba, SP. Bolsista do CNPq. E-mail: estumarisa@yahoo.com.br (2)Esalq, Dep. de Produção Vegetal. Bolsista do CNPq. E-mail: jacomino@esalq.usp.br (3)Esalq, Dep. de Produção Vegetal. E-mail: iubron@esalq.usp.br
\end{abstract}

\begin{abstract}
Resumo - O objetivo deste trabalho foi determinar índices de maturação adequados para avaliar a influência dos estádios de maturação nas transformações físico-químicas após a colheita de goiabas (Psidium guajava cv. Pedro Sato). Frutos colhidos nos estádios de maturação, segundo a cor da casca (1: verde-escura, 2: verde-clara e 3: verde-amarela), foram armazenados a $25 \pm 1^{\circ} \mathrm{C}$ e $80 \pm 5 \%$ UR e avaliados quanto às transformações físicas e químicas e percentual de podridão. No momento da colheita, a cor da casca, a firmeza da polpa e a relação sólidos solúveis totais/acidez total titulável apresentaram diferenças significativas entre os três estádios de maturação. Durante o amadurecimento, as transformações físico-químicas foram semelhantes entre os estádios de maturação. O período máximo de viabilidade do fruto para comercialização foi de dois, quatro e seis dias após a colheita, nos estádios 3, 2 e 1, respectivamente. Os teores de sólidos solúveis totais, acidez total titulável e ácido ascórbico apresentaram baixo coeficiente de correlação com as variáveis estudadas. A cor da casca, a firmeza da polpa e a relação sólidos solúveis totais/acidez total titulável foram considerados índices de maturação adequados para a goiaba 'Pedro Sato'.
\end{abstract}

Termos para indexação: Psidium guajava, amadurecimento.

\section{Indices to evaluate postharvest quality of guavas under different maturation stages}

\begin{abstract}
The aim of this work was to determine the maturation indices to evaluate the influence of maturation stages on physical and chemical transformations in guavas (Psidium guajava cv. Pedro Sato) after harvest. Guavas were harvested at maturation stages, according to the skin color, 1 (dark green), 2 (light green) and stage 3 (yellowish green), stored at $25 \pm 1^{\circ} \mathrm{C}$ and $85 \pm 5 \% \mathrm{RH}$, and assessed for physical and chemical transformations and decay. At harvest, the three maturation stages presented distinct results of skin color, pulp firmness and total soluble solids total titratable acidity ratio. During the ripening, physical and chemical transformations were similar among the maturation stages. The postharvest life of stages 3,2 and 1, was two, four and six days, respectively. The total soluble solids content, total titratable acidity and ascorbic acid presented low correlated coefficient with all variables studied. The skin color, the pulp firmness and the total soluble solids/total titratable acidity ratio can be considered acceptable maturation indexes for guava 'Pedro Sato'.
\end{abstract}

Index terms: Psidium guajava, ripening.

\section{Introdução}

O Brasil é um dos três maiores produtores mundiais de goiaba (Psidium guajava). A maior parte da produção é absorvida pela indústria, porém, no Estado de São Paulo, principal produtor nacional, houve um incremento de $17 \%$ na produção de goiabas para mesa no período de 2000-2001 (Instituto de Economia Agrícola, 2002).

A expansão do mercado consumidor de goiaba in natura está condicionada à qualidade dos frutos e ao aumento da vida útil pós-colheita. A goiaba é um fruto altamente perecível por causa do seu intenso metabolismo durante o amadurecimento. Os atributos de qualidade são influenciados pelas variedades, condições edafoclimáticas e práticas culturais. Manejos inadequados na colheita e na pós-colheita aceleram os processos de senescência afetando sensivelmente a qualidade e limitando ainda mais o período de comercialização. O estádio de maturação, em que os frutos são colhidos determina a qualidade do fruto a ser oferecido ao consumidor. Os frutos colhidos imaturos, além de pouca qualidade, têm alto índice de perda de água e são muito 
suscetíveis às desordens fisiológicas. Por outro lado, quando colhidos muito maduros, entram rapidamente em senescência (Manica et al., 2000).

A correta determinação do estádio de maturação em que um fruto se encontra é essencial para que a colheita seja efetuada no momento certo. Para isso, são utilizados os chamados índices de maturação. Esses índices compreendem medidas físico-químicas que sofrem mudanças ao longo da maturação dos frutos. Os índices de maturação devem assegurar a obtenção de frutas de boa qualidade, durante o armazenamento (Kluge et al., 2002). Em relação à goiaba, não existe padronização $\mathrm{e}$ consenso do estádio de maturação ideal para a colheita, assim como pouco se sabe a respeito dos índices de maturação adequados. As goiabas normalmente são colhidas quando a polpa ainda está firme e a coloração da casca começa a mudar de verde-escuro para verdeclaro ou começa a amarelecer (Manica et al., 2000). Estudos que avaliaram a influência dos estádios de maturação na evolução das características físicas e químicas desse fruto após a colheita são escassos.

O objetivo deste trabalho foi determinar os índices de maturação adequados para avaliar a influência de três estádios de maturação nas transformações físicas e químicas após a colheita de goiabas 'Pedro Sato'.

\section{Material e Métodos}

O experimento foi realizado no Laboratório de Pós-colheita do Departamento de Produção Vegetal da Escola Superior de Agricultura Luiz de Queiroz (EsalqUSP), Piracicaba, SP. Foram utilizadas goiabas da variedade Pedro Sato, provenientes de pomar comercial localizado no Município de Vista Alegre, SP $\left(48^{\circ} 21^{\prime} \mathrm{W}\right.$ e $\left.21^{\circ} 10^{\prime} \mathrm{S}\right)$.

Foram selecionados frutos sem defeitos com massa média de $170 \pm 10 \mathrm{~g}$. A cor da casca foi medida com colorímetro Minolta e os frutos foram separados nos estádios de maturação segundo o seguinte critério: estádio 1 , cor da casca verde-escura, ângulo de cor $\left({ }^{\circ} \mathrm{h}\right)$ entre 120 e 117; estádio 2, cor da casca verde-clara, ângulo de cor $\left({ }^{\circ} \mathrm{h}\right)$ entre 116 e 113 ; estádio 3, cor da casca verde-amarela, ângulo de cor $\left({ }^{\circ} \mathrm{h}\right)$ entre 112 e 108 (Figura 1). Os frutos foram armazenados em câmara, com controle de temperatura e umidade, a $25 \pm 1^{\circ} \mathrm{C}$ e $85 \pm 5 \%$ UR.

As análises físicas e químicas foram realizadas no momento da colheita e a cada dois dias durante o período no qual as goiabas apresentavam características viá- veis de comercialização. Foram considerados inviáveis à comercialização lotes com mais de $30 \%$ de frutos com podridão, aspecto de murchamento e supermaduros. A cor da casca e da polpa foram determinadas com o colorímetro Minolta, modelo CR-300. Em relação à cor da casca, efetuaram-se duas leituras por fruto, em lados opostos da sua região equatorial, e os resultados foram expressos em ângulo de cor $\left({ }^{\circ} \mathrm{h}\right)$. A cor da polpa foi determinada efetuando-se uma leitura no centro da região placentária de cada fruto, após o corte transversal dos mesmos e os resultados expressos em cromaticidade (C). A firmeza da polpa foi determinada com penetrômetro digital, ponteira com $8 \mathrm{~mm}$ de diâmetro e ponta plana, tomando-se duas leituras por fruto em lados opostos de sua região equatorial, após retirada da casca e os resultados expressos em Newton (N). Os sólidos solúveis totais (SST) foram determinados por leitura direta em refratômetro digital ATTO-2WAJ e os resultados expressos em ${ }^{\circ}$ Brix; a acidez total titulável (ATT) foi determinada de acordo com Carvalho et al. (1990), em que $10 \mathrm{~g}$ de polpa foram homogeneizadas em $90 \mathrm{~mL}$ de água destilada. A suspensão foi titulada com $\mathrm{NaOH} 0,1 \mathrm{~N}$ para a neutralização dos ácidos orgânicos, o que ocorre quando a solução atinge o $\mathrm{pH} 8,10$, com resultados expressos em porcentagem de ácido cítrico. A relação SST/ATT foi obtida pela razão entre os valores de sólidos solúveis totais e acidez total titulável. O teor de ácido ascórbico foi determinado conforme Carvalho et al. (1990) e os resultados expressos em mg de ácido ascórbico por $100 \mathrm{~g}$ de polpa. A porcentagem de podridão foi determinada pela contagem de goiabas com presença de podridão. Foram considerados podres os frutos com lesões com mais de $0,3 \mathrm{~cm}$ e os resultados expressos em porcentagem de goiabas com podridão. A perda de massa fresca foi determinada pela diferença entre a massa do fruto no momento da colheita e após o período de armazenamento e os resultados foram expressos em porcentagem.

O delineamento estatístico utilizado foi inteiramente casualizado com cinco repetições de três frutos para cada tratamento e período de análise. Os dados foram submetidos à análise de variância utilizando-se o Sistema de Análise Estatística (SANEST) e as médias foram comparadas pelo teste de Tukey a 5\% de probabilidade. Os resultados das análises também foram submetidos à análise do desvio-padrão. As diferenças entre dois tratamentos maiores que a soma de dois desvios-padrões foram consideradas significativas. 
Com o objetivo de estabelecer as correlações existentes entre as variáveis estudadas nos diferentes estádios de maturação, foram calculados os coeficientes de correlação entre as variáveis estudadas. Os coeficientes foram obtidos a partir da seguinte equação:

$$
\begin{aligned}
& \mathrm{R}=\frac{\sum\left(\mathrm{x}_{\mathrm{i}}-\overline{\mathrm{x}}\right)\left(\mathrm{y}_{\mathrm{i}}-\overline{\mathrm{y}}\right)}{\left[\sum\left(\mathrm{x}_{\mathrm{i}}-\overline{\mathrm{x}}\right)^{2} \sum\left(\mathrm{y}_{\mathrm{i}}-\overline{\mathrm{y}}\right)^{2}\right]^{1 / 2}}= \\
& =\frac{\left(\sum \mathrm{x}_{\mathrm{i}} \mathrm{y}_{\mathrm{i}}\right)-\left(\sum \mathrm{x}_{\mathrm{i}}\right)\left(\sum \mathrm{y}_{\mathrm{i}}\right) / \mathrm{n}}{\left\{\left[\left(\sum \mathrm{x}_{\mathrm{i}}^{2}\right)-\left(\sum \mathrm{x}_{\mathrm{i}}\right)^{2} / \mathrm{n}\right]\left[\left(\sum \mathrm{y}_{\mathrm{i}}^{2}\right)-\left(\sum \mathrm{y}_{\mathrm{i}}\right)^{2} / \mathrm{n}\right]\right\}^{1 / 2}}=\hat{\mathrm{a}} \frac{\mathrm{S}_{\mathrm{x}}}{\mathrm{S}_{\mathrm{y}}}
\end{aligned}
$$

em que:

$X$ e $Y$ são variáveis aleatórias e $S_{x}, S_{y}$ são os desviospadrões estimados em relação às médias.
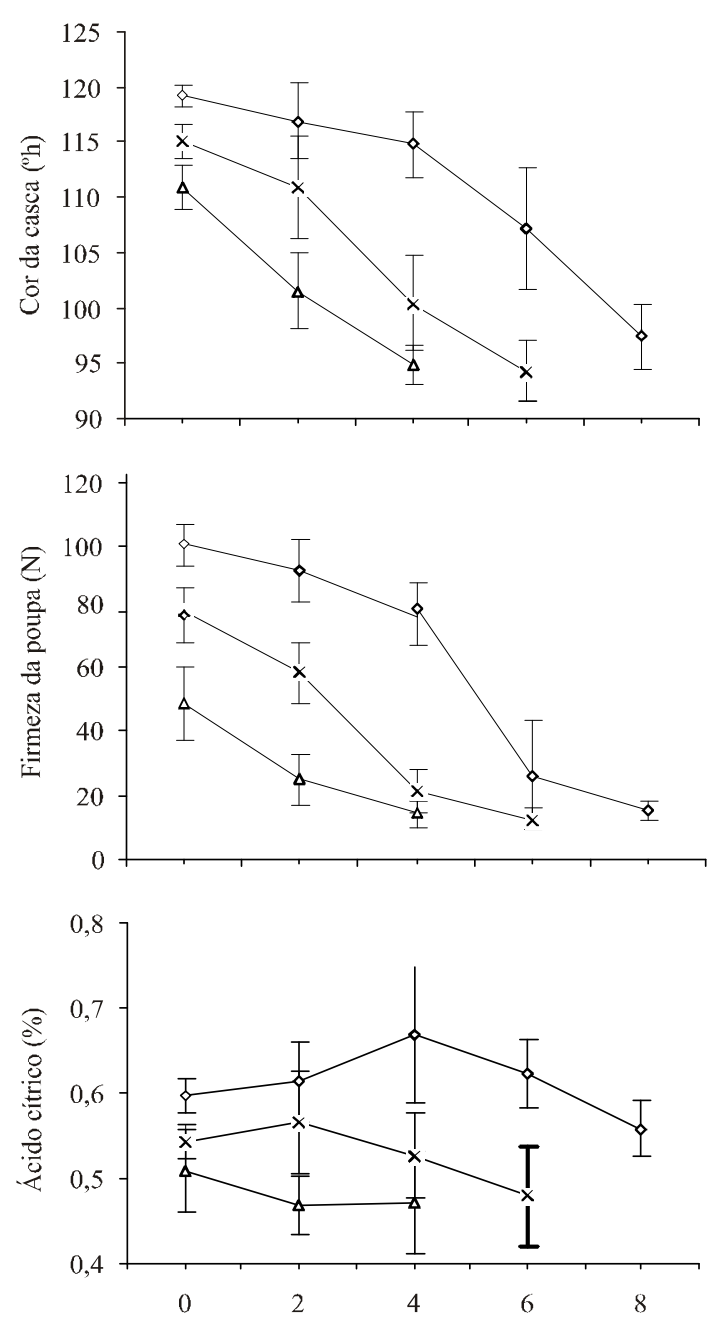

\section{Resultados e Discussão}

No momento da colheita, a utilização da cor da casca na distinção dos estádios de maturação revelou-se viável, considerando as outras diferenças significativas apresentadas entre as demais variáveis analisadas (Tabela 1). Esta variável apresentou baixo coeficiente de variação, oferecendo confiabilidade da medida. $\mathrm{O}$ ângulo de cor $\left({ }^{\circ} \mathrm{h}\right)$ expressa de modo significativo as diferenças na coloração da casca, permitindo uma visualização precisa da mudança de cor. Esses resultados estão de acordo com os de Mercado-Silva et al. (1998), que consideraram a cor da casca como o melhor índice na determinação do estádio de maturação da goiaba 'Media China'.
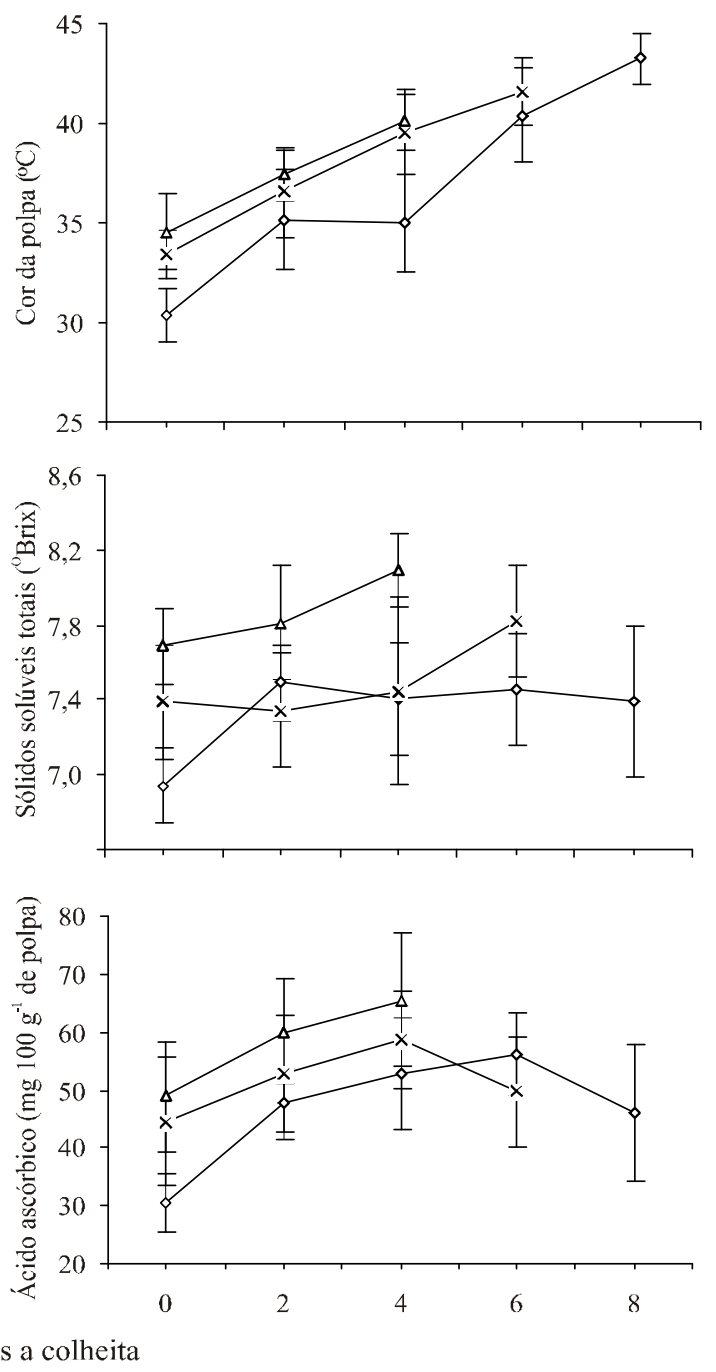

Figura 1. Influência dos estádios de maturação $1(\diamond), 2(x)$ e $3(\Delta)$, correspondendo a frutos colhidos com cor da casca verde-escura, verde-clara e verde-amarela, respectivamente, nas transformações físico-químicas, durante armanezamento, a $25^{\circ} \mathrm{Ce} 80 \% \mathrm{UR}$, até 8 dias após a colheita. As barras verticais em cada ponto representam a média \pm desvio-padrão. 
A cor da casca apresentou diminuição dos valores de ângulo $\left({ }^{\circ} h\right)$ em todos os estádios de maturação, durante o armazenamento, indicando a mudança de cor verde para amarela (Figura 1). A coloração totalmente amarela foi observada quando os frutos atingiram ângulo de cor menor que 100 (Figura 1). Os principais processos envolvidos na perda da coloração verde dos frutos durante o amadurecimento são a degradação da clorofila e a síntese de caroteno (Cross, 1987).

A firmeza da polpa separou de modo significativo os três estádios de maturação na colheita (Tabela 1). A firmeza do estádio 2 foi $23,1 \%$ menor que a do estádio 1 . Nos frutos colhidos no estádio 3 , a firmeza foi $40,3 \%$ menor que a firmeza dos frutos colhidos no estádio 2 e cerca da metade da firmeza dos frutos colhidos no estádio 1. Estes resultados estão próximos dos obtidos por Dhingra et al. (1983), os quais consideraram verdes as goiabas com firmeza acima de $85 \mathrm{~N}$ e verde-amarelas goiabas com firmeza entre $55,11 \mathrm{~N} \mathrm{e}$ $66,3 \mathrm{~N}$.

Os três estádios apresentaram comportamento semelhante em relação à perda de firmeza da polpa, durante o armazenamento (Figura 1). Os frutos sofreram rápida perda de firmeza da polpa independentemente do estádio de maturação, corroborando os dados obtidos por Piveta et al. (1992). A firmeza teve intensa redução no estádio 3, entre zero e dois dias, de 48,3 N para $24,9 \mathrm{~N}$, no estádio 2, entre dois e quatro dias, de $58,21 \mathrm{~N}$ para $21,14 \mathrm{~N}$ e no estádio 1 , entre quatro e seis dias, de $77,92 \mathrm{~N}$ para $26,15 \mathrm{~N}$. Essa rápida perda da

Tabela 1. Características físico-químicas de goiabas 'Pedro Sato' em três estádios de maturação, no momento da colheita ${ }^{(1)}$.

\begin{tabular}{lrcrr}
\hline Índice de maturação $^{(2)}$ & \multicolumn{4}{c}{ Estádio de maturação $^{(3)}$} \\
\cline { 2 - 5 } & Estádio 1 & Estádio 2 & Estádio 3 & CV (\%) \\
\hline Cor da casca ( $\left.{ }^{\circ} \mathrm{h}\right)$ & $119,17 \mathrm{a}$ & $115,03 \mathrm{~b}$ & $110,89 \mathrm{c}$ & 1,3 \\
Firmeza (N) & $100,80 \mathrm{a}$ & $77,60 \mathrm{~b}$ & $46,30 \mathrm{c}$ & 13,1 \\
Cor da polpa (Croma) & $30,36 \mathrm{a}$ & $33,38 \mathrm{~b}$ & $34,57 \mathrm{~b}$ & 7,8 \\
SST ( ${ }^{\circ}$ Brix) & $6,90 \mathrm{a}$ & $7,30 \mathrm{ab}$ & $7,60 \mathrm{~b}$ & 9,3 \\
ATT (\% de ácido cítrico) & $0,60 \mathrm{a}$ & $0,54 \mathrm{~b}$ & $0,51 \mathrm{~b}$ & 8,7 \\
Relação SST/ATT & $11,60 \mathrm{a}$ & $13,60 \mathrm{~b}$ & $15,10 \mathrm{c}$ & 10,7 \\
Vit. C & $30,35 \mathrm{a}$ & $44,47 \mathrm{ab}$ & $48,77 \mathrm{~b}$ & 21,7 \\
\hline
\end{tabular}

${ }^{(1)}$ Médias seguidas pela mesma letra na linha não diferem entre si pelo teste de Tukey, a 5\% de probabilidade. ${ }^{(2)} \mathrm{SST}$ : sólidos solúveis totais; ATT: acidez total titulável; Vit. C: vitamina C (mg de ácido ascórbico $100 \mathrm{~g}^{-1}$ de polpa. ${ }^{(3)}$ Estádio 1: casca verde-escura; estádio 2: casca verdeclara; estádio 3: casca verde-amarela. firmeza durante o amadurecimento de goiabas pode ser creditada às atividades das enzimas hidrolíticas, como a poligalacturonase e pectinametilesterase (Jain et al., 2001), que promovem intensa solubilização das pectinas constituintes da parede celular, resultando em perda de firmeza (Tucker, 1993).

A cor da polpa não apresentou diferenças significativas em relação à intensidade da coloração (cromaticidade) entre os três estádios na colheita (Tabela 1). Entretanto, houve diferenças em relação ao desenvolvimento da coloração dos tecidos do mesocarpo (Figura 2). No momento da colheita, os frutos no estádio 1 apresentavam coloração vermelha somente nos tecidos da placenta, enquanto nos frutos nos estádios 2 e 3, os tecidos do mesocarpo também apresentavam desenvolvimento da coloração vermelha.

O aumento da cromaticidade em todos os estádios indica a mudança de cor rosa para vermelho intenso e é provavelmente decorrente da biossíntese de licopeno (Cross, 1987). A cor da polpa foi semelhante entre os estádios 2 e 3 e mais intensa nestes do que no estádio 1 durante o período de armazenamento (Figura 1).
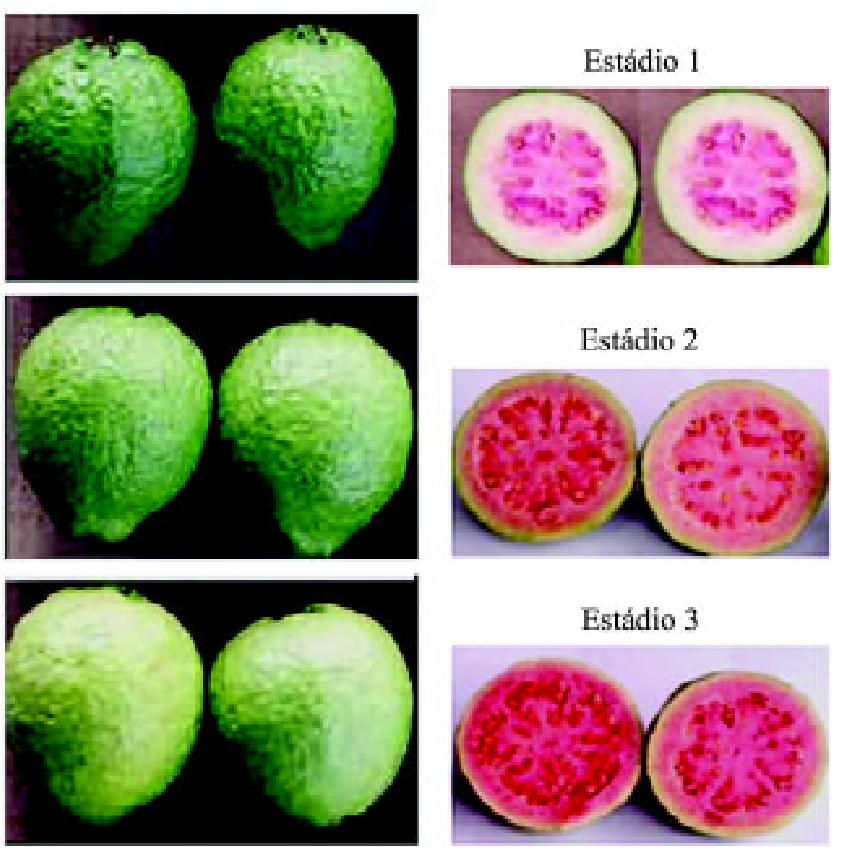

Figura 2. Estádios de maturação de goiabas 'Pedro Sato', classificados segundo a cor da casca, em estádio 1 (cor da casca verde-escura, ângulo de cor entre $120^{\circ} \mathrm{h}$ e $117^{\circ} \mathrm{h}$ ), estádio 2 (cor da casca verde-clara, ângulo de cor entre $116^{\circ} \mathrm{h}$ e $113^{\circ} \mathrm{h}$ ) e estádio 3 (cor da casca verde-amarela, ângulo de cor entre $112^{\circ} \mathrm{h}$ e $108^{\circ} \mathrm{h}$ ), no momento da colheita. 
O teor de sólidos solúveis totais (SST), que geralmente é utilizado como índice de maturação, não apresentou capacidade discriminante dos estádios de maturação na época da colheita. O teor SST diferenciou o estádio 3 do estádio $1 \mathrm{em}$ apenas $0,7^{\circ} \mathrm{Brix}$, e o estádio 2 apresentou valores intermediários (Tabela 1). De forma semelhante, Mercado-Silva et al. (1998) verificaram que o teor de SST em goiaba não representa um bom índice na caracterização dos estádios de maturação dos frutos. Em goiaba, os açúcares totais representam cerca de $51 \%$ a $91 \%$ do teor de sólidos solúveis (Rathore, 1976; Chitarra et al., 1981), e o principal açúcar é a frutose. Portanto, o teor de SST está sob influência de fatores que afetam a síntese da frutose. $\mathrm{O}$ amido, que em altas concentrações em maçã e banana aumenta o teor de SST durante o amadurecimento, em goiabas representa $1 \%$ a $3 \%$ do total dos carboidratos não estruturais (Ali \& Lazan, 1997), não apresentando este efeito. O teor de SST está sujeito a inúmeras variações, o que dificulta o estabelecimento de um intervalo que represente um estádio de maturação.

Os teores de SST apresentaram poucas mudanças durante o amadurecimento dos frutos em todos os estádios de maturação (Figura 1). Resultados semelhantes foram encontrados por Jacomino (1999) em goiabas 'Kumagai'.

A acidez total titulável (ATT), no momento da colheita, foi maior no estádio 1 do que nos demais estádios, porém não separou estatisticamente os estádios 2 e 3 (Tabela 1). Piveta et al. (1992), observaram, na cultivar Paluma, valores maiores de acidez nos frutos colhidos nos estádio verde que nos frutos colhidos nos estádios mais maduros.

O porcentual de acidez total titulável foi crescente até o segundo e quarto dia após a colheita nos frutos colhidos nos estádios 2 e 1 , respectivamente, ao passo que no estádio 3, ela foi decrescente a partir da colheita (Figura 1). Jacomino et al. (2002) em goiabas 'Kumagai' e Lima \& Durigan (2000), em goiabas 'Pedro Sato', também observaram um leve aumento no teor de ATT, durante o armazenamento em diferentes embalagens, sob refrigeração a $10^{\circ} \mathrm{C}$. Mattiuz (2002), avaliando o efeito de danos mecânicos em goiabas 'Pedro Sato' e 'Paluma', observou aumento dos teores de acidez até o quarto dia após a colheita. Os ácidos orgânicos representam um dos principais substratos para os processos respiratórios durante o amadurecimento e de forma geral tendem a diminuir significativamente durante esta fase (Tucker, 1993).
Diferentemente dos teores de SST e ATT, a relação entre estas variáveis (SST/ATT) foi um índice que diferenciou os três estádios de maturação (Tabela 1). Estes resultados estão de acordo com os de Tripathi \& Gangwar (1971) e Chitarra et al. (1981), os quais sugerem a utilização da relação SST/ATT como índice de maturação para goiabas.

O teor de ácido ascórbico apresentou diferenças significativas somente entre os estádios 1 e 3 e os teores maiores de ácido ascórbico ocorreram nos frutos em estádios mais avançados de maturação (Tabela 1). ElBulk et al. (1997) também observaram teores crescentes de ácido ascórbico durante a maturação nas cultivares Shambati, Pakistani, Shendi e Ganib.

Durante o armazenamento, inicialmente ocorreu um aumento no teor de ácido ascórbico em todos os estádios de maturação, com posterior diminuição (Figura 1). Jacomino (1999), trabalhando com goiabas brancas 'Kumagai' armazenadas a $10^{\circ} \mathrm{C}$ em diferentes embalagens, também observou aumento no teor de ácido ascórbico durante o amadurecimento dos frutos. Segundo Mercado-Silva et al. (1998), o aumento no teor de ácido ascórbico em goiabas durante o início do amadurecimento está associado ao aumento da síntese de intermediários metabólicos, os quais são precursores do ácido ascórbico. A degradação de polissacarídeos da parede celular possivelmente resulta em um aumento da galactose que é um dos precursores da biossíntese do ácido ascórbico (Wheeler et al., 1998; Smirnoff et al., 2001). Com o decorrer do amadurecimento ocorre a oxidação dos ácidos com conseqüente redução do teor de ácido ascórbico, indicando a senescência do fruto (Tucker, 1993).

A utilização de mais de uma variável na determinação do estádio de maturação possibilita caracterizar de forma mais precisa o estádio de desenvolvimento do fruto. Entretanto, conhecendo-se o grau de relação entre as variáveis, é possível avaliar uma variável em função da outra. As melhores relações ocorreram entre a cor da casca, cor e firmeza da polpa, o que pode ser verificado pelo alto coeficiente de correlação obtido entre estas variáveis (Tabela 2). Os teores de SST, ATT e ácido ascórbico apresentaram baixo coeficiente de correlação com todas as variáveis estudadas, em razão das discretas mudanças que tais variáveis sofreram durante o amadurecimento, ao contrário das intensas mudanças na cor das casca e da polpa e na firmeza da polpa.

Os frutos apresentaram períodos de conservação diferentes em razão do estádio de maturação no momento da colheita. A podridão foi uma das principais causas de redução do período comercializável (Figura 3). 
Tabela 2. Coeficientes de correlação de variáveis físico-químicas de goiabas 'Pedro Sato' colhidas em três estádios de maturação ${ }^{(1)}$.

\begin{tabular}{lccccc}
\hline Variáveis $^{(2)}$ & $\begin{array}{c}\text { Cor da } \\
\text { polpa }\left({ }^{\circ} \mathrm{h}\right)\end{array}$ & $\begin{array}{c}\text { Firmeza } \\
(\mathrm{N})\end{array}$ & $\begin{array}{c}\text { SST } \\
\left({ }^{\circ} \text { Brix }\right)\end{array}$ & $\begin{array}{c}\text { ATT }(\%) \\
\text { Ácido ascórbico } \\
\left(\mathrm{mg} 100 \mathrm{~g}^{-1}\right)\end{array}$ \\
\hline Cor da casca & $-0,75^{*}$ & $0,80^{*}$ & $0,24^{\mathrm{ns}}$ & $0,54^{* *}$ & $0,25^{\mathrm{ns}}$ \\
Cor da polpa & & $-0,77^{*}$ & $0,04^{\mathrm{ns}}$ & $-0,31^{\mathrm{ns}}$ & $0,05^{\mathrm{ns}}$ \\
Firmeza & & & $0,08^{\mathrm{ns}}$ & $0,55^{* *}$ & $0,08^{\mathrm{ns}}$ \\
SST & & & & $-0,05^{\mathrm{ns}}$ & $0,04^{\mathrm{ns}}$ \\
ATT & & & & & $0,03^{\mathrm{ns}}$ \\
\hline
\end{tabular}

${ }^{(1)}$ Estádio de maturação 1, 2 e 3, correspondendo a frutos colhidos com cor da casca verde-escura, verde clara e verde-amarela, respectivamente. (2)Variáveis físicas e químicas considerando os três estádios de maturação; SST: sólidos solúveis totais; ATT: acidez total titulável. " ${ }^{n}$ Não-significativo.* e ${ }^{* *}$ Significativo a $5 \%$ e a $1 \%$ de probabilidade, respectivamente.
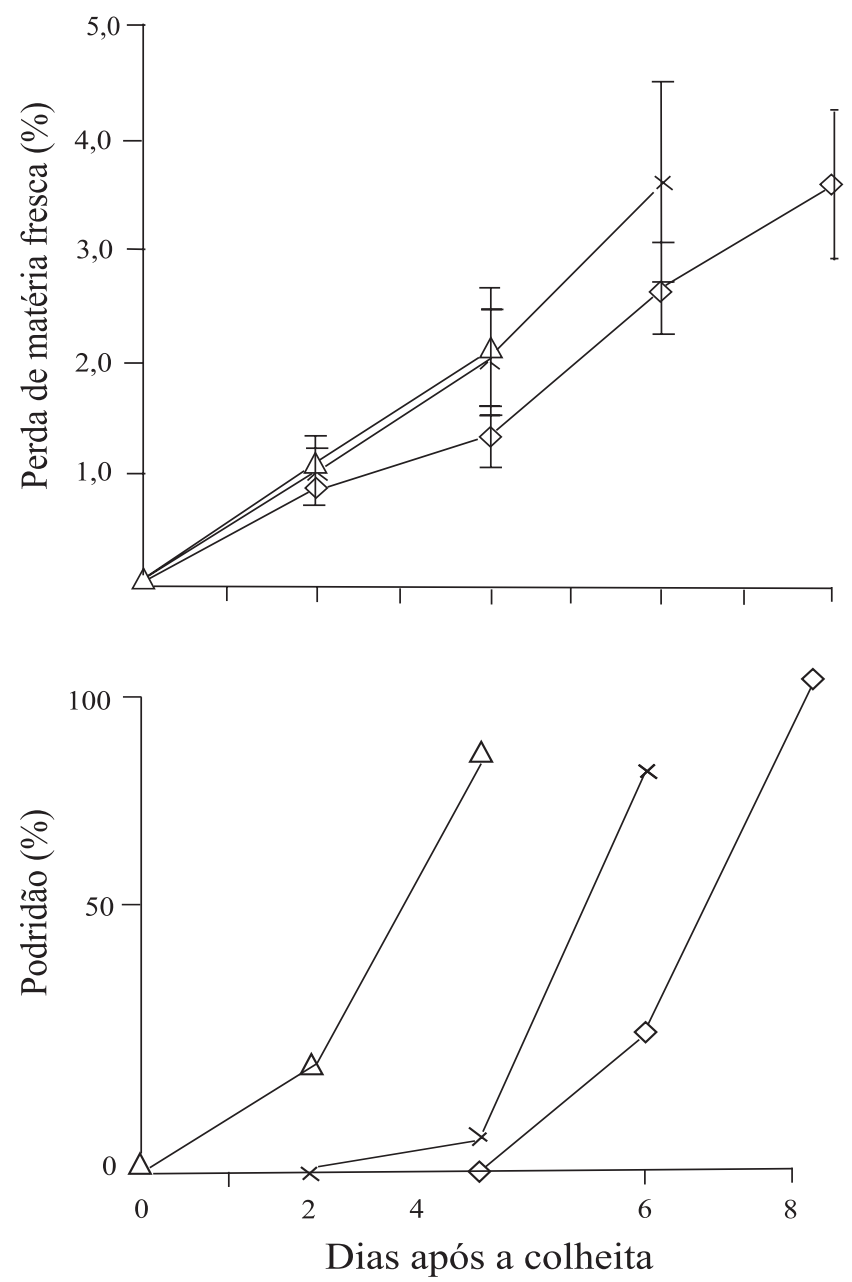

Figura 3. Influência dos estádios de maturação $1(\diamond), 2(x)$ e $3(\Delta)$ correspondendo a frutos colhidos com cor da casca verde-escura, verde-clara e verde-amarela, respectivamente, na perda de massa de goiabas 'Pedro Sato' e na porcentagem de podridão, durante armanezamento a $25^{\circ} \mathrm{C}$ e $80 \%$ UR, até 8 dias após a colheita. As barras em cada ponto representam a média \pm desvio-padrão.
Os frutos colhidos no estádio 1 apresentaram período de comercialização de seis dias e os frutos colhidos nos estádios 2 e 3 tiveram este período reduzido para quatro e dois dias, respectivamente.

A perda de massa fresca atingiu valores máximos de $3,5 \%$ em relação à massa inicial durante o período de armazenamento (Figura 3). Os estádios de maturação apresentaram pouca influência nesta variável. A perda de massa fresca dos frutos é uma variável importante que está diretamente relacionada com a qualidade do fruto. Segundo Ben-Yehoshua (1985), um dos principais problemas durante o armazenamento de frutas e hortaliças é a perda de massa por causa do processo de transpiração. A perda de água leva ao amolecimento dos tecidos, tornando os frutos mais suscetíveis às deteriorações e a alterações na cor e sabor.

As transformações físico-químicas apresentaram comportamento semelhante nos três estádios de maturação, após a colheita. Entretanto, as diferenças observadas no momento da colheita e o período de comercialização viável referente a cada estádio demostraram que os frutos apresentavam estádios diferentes de maturação. Os frutos atingiram o completo amadurecimento independentemente do estádio de maturação no qual foram colhidos. Isto permite afirmar que mesmo os frutos do estádio 1 apresentavam maturidade fisiológica, ou seja, capacidade de continuar sua ontogenia após a colheita (Watada et al., 1984).

\section{Conclusões}

1. A cor da casca, a firmeza da polpa e a relação sólidos solúveis totais/acidez total titulável são índices adequados de maturação para goiabas 'Pedro Sato'.

2. Os teores de sólidos solúveis totais, de acidez total titulável e de ácido ascórbico não são indicadores adequados do estádio de maturação em goiabas 'Pedro Sato'.

3. Goiabas 'Pedro Sato' colhidas em diferentes estádios de maturação apresentam comportamento semelhante quanto às transformações físico-químicas, após a colheita.

\section{Referências}

ALI, Z.M.; LAZAN, H. Guava. In: MITRA, S.K. Postharvest of physiology and storage of tropical and subtropical fruits. Wallingford: CAB International, 1997. p.145-165. 
BEN-YEHOSHUA, S. Individual seal-packaging of fruit and vegetables in plastic film: a new postharvest technique. HortScience, v.20, p.32-37, 1985.

CARVALHO, C.R.L.; MANTOVANI, D.M.B.; CARVALHO, P.R.N.; MORAES, R.M.M. Análises químicas de alimentos. Campinas: Instituto de Tecnologia de Alimentos, 1990. 121p.

CHITARRA, M.I.F.; CHITARRA, A.B.; CARVALHO, V.D. Algumas características dos frutos de duas cultivares de goiabeira (Psidium guajava L.) em fase de maturação. In: CONGRESSO BRASILEIRO DE FRUTICULTURA, 6., 1981, Recife. Anais. Recife: Sociedade Brasileira de Fruticultura, 1981. v.2, p.771-780.

CROSS, J. Pigments in fruit. London: Academic, 1987. 303p.

DHINGRA, M.K.; GUPTA, O.P.; CHUNDAWAT, B.S. Studies on pectin yield ad quality of some guava cultivates in relation to cropping season and fruit maturity. Journal of Food Science and Technology, v.20, p.10-13, 1983.

EL-BULK, R.E.; EL BABIKER, F.E.; EL TINAY, A.H. Changes in chemical composition of fruits during development and ripening. Food Chemistry, v.59, p.395-399, 1997.

INSTITUTO DE ECONOMIA AGRÍCOLA (São Paulo, SP). Valor da produção. Disponível em: 〈www.iea.sp.gov〉. Acesso em: 15 out. 2002.

JACOMINO, A.P. Conservação de goiabas 'Kumagai' em diferentes temperaturas e materiais de embalagem. 1999. 90p. Tese (Doutorado) - Escola Superior de Agricultura Luiz de Queiroz, Piracicaba.

JACOMINO, A.P.; KLUGE, R.A.; BRACKMANN, A.; CASTRO, P.R. de C. Amadurecimento e senescência de mamão com 1-metilciclopropeno. Scientia Agricola, v.59, p.303-308, 2002.

JAIN, N.; DHAWAN, K.; MALHOTRA, S.P.; SIDDIQUI, S.; SINGH, R. Compositional and enzymatic changes in guava (Psidium guajava L.) fruits during ripening. Acta Physiologiae Plantarum, v.23, p.357-362, 2001.

KLUGE, R.A.; NACHTIGAL, J.C.; BILHALVA, A.B. Fisiologia e manejo pós-colheita de frutas de clima temperado. 2.ed. Pelotas: UFPel, 2002. 163p.
LIMA, M.A.; DURIGAN, J.F. Conservação de goiabas 'Pedro Sato' associando-se refrigeração com diferentes embalagens. Revista Brasileira de Fruticultura, v.22, p.232-236, 2000.

MANICA, I.; ICUMA, I.M.; JUNQUEIRA, N.T.V.; SALVADOR, J.O.; MOREIRA, A.; MALAVOLTA, E. Fruticultura tropical: goiaba. Porto Alegre: Cinco Continentes, 2000. 373p.

MATTIUZ, B. Fisiologia e qualidade pós colheita de goiabas. 2002. 118p. Tese (Doutorado) - Universidade Estadual Paulista Júlio de Mesquita Filho, Jaboticabal.

MERCADO-SILVA, E.; BAUTISTA, P.B.; GARCIA-VELASCO, M.A. Fruit development, harvest index ripening changes of guavas produced in central Mexico. Postharvest Biology and Technology, v.13, p.143-150, 1998.

PIVETA, K.F.L.; DURIGAN, J.F.; PEREIRA, F.M. Avaliação da conservação pós-colheita, em condições ambientais, de frutos de goiabeira (Psidium guajava L.) colhidos em diferentes estádios de maturação. Revista Brasileira de Fruticultura, v.14, p.236-239, 1992.

RATHORE, D.S. Effect of season on growth and chemical composition of guava (Psidium guajava L.) fruits. Journal of Horticultural Science, v.51, p.41-47, 1976.

SMIRNOFF, N.; CONKLIN, P.; LOEWUS, F.A. Biosynthesis of ascorbic acid in plants: a renaissance. Annual Review of Plant Physiology and Plant Molecular Biology, v.52, p.437-467, 2001.

TRIPATHI, R.S.; GANGWAR, B.M. Biochemical changes as indices of maturity in guava (Psidium guajava L.). Progressive Horticulturae, v.3, p.17-23, 1971.

TUCKER, G.A. Introduction. In: SEYMOUR, G.B.; TAYLOR, J.E.; TUCKER, G.A. (Ed.). Biochemistry of fruit ripening. London: Chapman \& Hall, 1993. p.2-51.

WATADA, A.E.; HERNER, R.C.; KADER, A.A.; ROMANI, R.J.; STABY, G.L. Terminology for the description of developmental stages of horticultural crops. HortScience, v.19, p.20-21, 1984.

WHEELER, G.L.; JONES, M.A.; SMIRNOFF, N. The biosynthetic pathway of vitamin C in higher plants. Nature, v.393, p.365-369, 1998.

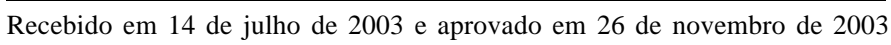

